\title{
Challenging Thermodynamics: Hydrogenation of Benzene to 1,3- Cyclohexadiene by Ru@Pt Nanoparticles
}

\author{
Andreas Weilhard, ${ }^{[a, b]}$ Gabriel A. Abarca, ${ }^{[a]}$ Janine Viscardi, ${ }^{[a]}$ Martin H. G. Prechtl, ${ }^{*[c]}$ Jackson D. \\ Scholten, ${ }^{\left[{ }^{[a]}\right.}$ Fabiano Bernardi, ${ }^{[a]}$ Daniel L. Baptista ${ }^{[a]}$ and Jairton Dupont ${ }^{\star[a, b]}$ \\ Dedicated to Prof. Faruk Nome (UFSC-Brazil) in the occasion of his $65^{\text {th }}$ anniversary.
}

\begin{abstract}
Since the earliest reports on catalytic benzene hydrogenation, 1,3-cyclohexadiene and cyclohexene have been proposed as key intermediates. However, the former has never been obtained with remarkable selectivity. Herein we report the first partial hydrogenation of benzene towards 1,3 cyclohexadiene under mild conditions in a catalytic biphasic system consisting of Ru@Pt nanoparticles (NPs) in ionic liquid (IL). The tandem reduction of $\left[R u(C O D)(2 \text {-methylallyl })_{2}\right]$ (COD $=1,5$-cyclooctadiene) followed by decomposition of $\left[\mathrm{Pt}_{2}(\mathrm{dba})_{3}\right]$ (dba = dibenzylideneacetone) in 1- $n$ butyl-3-methylimidazolium hexafluorophosphate $\left(\mathrm{BMI}^{\left.\mathrm{P} \mathrm{PF}_{6}\right)} \mathrm{IL}\right.$ under hydrogen affords core-shell Ru@Pt NPs of $2.9 \pm 0.2 \mathrm{~nm}$. The hydrogenation of benzene $\left(60{ }^{\circ} \mathrm{C}, 6\right.$ bar of $\left.\mathrm{H}_{2}\right)$ dissolved in $n$ heptane by these bimetallic NPs in $\mathrm{BMI}^{-P_{6}} 6$ affords 1,3cyclohexadiene in unprecedented $21 \%$ selectivity at $5 \%$ benzene conversion. On opposition, almost no 1,3-cyclohexadiene was observed using monometallic $\mathrm{Pt}(0)$ or $\mathrm{Ru}(0) \mathrm{NPs}$ under the same reaction conditions and benzene conversions. The study reveals that the selectivity is related to synergetic effects of the bimetallic composition of the catalyst material as well as the performance under biphasic reaction conditions. It is proposed that colloidal metal catalysts in ILs and under multiphase conditions ("dynamic asymmetric mixture") can operate far from the thermodynamic equilibrium akin to chemically active membranes.
\end{abstract}

\section{Introduction}

Benzene hydrogenation is one of the most investigated reactions by metal NPs in view of its industrial applications and appealing basic surface science. ${ }^{[1-8]}$ It is assumed that the hydrogenation of benzene proceeds stepwise, i.e. coordination of the aromatic to the metal-surface followed by its reduction to

[a] A. Weilhard, Dr. G. A. Abarca, J. Viscardi, Prof. J. D. Scholten, Prof. F. Bernardi, Prof. D. L. Baptista and Prof. J. Dupont

Institute of Chemistry and Institute of Physics - UFRGS

Av. Bento Gonçalves, 9500 Porto Alegre 91501-970 RS Brazil

E-mail: jairton.dupont@nottingham.ac.uk

jackson.scholten@ufrgs.br

[b] Prof. J. Dupont

School of Chemistry - University of Nottingham

NG7 2RD Nottingham UK

[c] Priv.-Doz. Dr. M. H. G. Prechtl

University of Cologne, Department of Chemistry, Greinstr. 6,

Cologne, Germany.

E-mail: martin.prechtl@uni-koeln.de

Supporting information for this article is given via a link at the end of the document. 1,3-cyclohexadiene ( $\mathrm{CHD}$ ) than to cyclohexene ( $\mathrm{CHE}$ ) and finally to the thermodynamic cyclohexane $(\mathrm{CHA})$ product. ${ }^{[1]}$ While the partial hydrogenation of benzene to $\mathrm{CHE}$ is quite a challenge ${ }^{[0]}$ it can be performed at the industrial scale with relatively high selectivities employing modified $\mathrm{Ru}$ nanocatalysts. ${ }^{[10]}$ However, the preparation of monohydrogenated products (CHDs) is still a challenge even in terms of detection under catalytic hydrogenation conditions, since under standard conditions the reaction of benzene and $\mathrm{H}_{2}$ to CHDs is $13 \mathrm{kcal} / \mathrm{mol}$ uphill in free energy. This catalytic reaction is therefore thermodynamically impossible. In this vein, firstprinciples DFT calculation mechanism of benzene hydrogenation over $\mathrm{Pt}(111)$ suggest that $\mathrm{CHD}$ and $\mathrm{CHE}$ are expected to be at best minor products, since they are not formed along the dominant reaction path. The only product that can desorb is $\mathrm{CHA}$, and the most-abundant reaction mixture contains benzene and hydrogen. ${ }^{[11-12]}$ Nonetheless, CHE and CHDs have been obtained during hydrogenation of benzene promoted by lanthanide NPs in ammonia, albeit in virtually stoichiometric conditions. ${ }^{[13]}$ Interestingly, CHD is also usually observed as intermediate during the dehydrogenation of $\mathrm{CHE}$ or $\mathrm{CHA}$ by Pt catalysts. ${ }^{[14-15]}$

Others ${ }^{[16]}$ and $\mathrm{we}^{[17]}$ have already demonstrated that Ru NPs modified by ILs are quite effective and selective catalysts for the partial hydrogenation of benzene to $\mathrm{CHE}$, but no $\mathrm{CHDs}$ have been detected so far. We have envisioned that the selectivity of this reaction may be improved by controlling the electronic properties of the NPs, the atomic geometry of the NPs' surface atoms in the ILs, the reactions conditions (temperature, pressure and benzene concentration), and by using multiphase conditions, for example, by extracting the formed $\mathrm{CHE}$ from a NPs/lL/benzene phase. Therefore, working far from the thermodynamic equilibrium, ideally in non-equilibrium thermodynamic conditions, it will be possible to achieve higher $\mathrm{CHE}$ selectivities, at least at the very early stages of benzene hydrogenation.

Activation of the Pt catalytic centre (using which, $\mathrm{CHD}$ is formed during dehydrogenation of $\mathrm{CHE}$ ) may be induced by the introduction of Ru as a second component in a bimetallic NP. ${ }^{[18-}$ 19] Analogous observations in terms of electronic modifications have been made with Pd@Au NPs in dehalogenation reactions, ${ }^{[20]}$ hydrogenation reactions, ${ }^{[21]} \mathrm{Pt} @ \mathrm{Co}^{[22]}$ and Pd@Ag NPs for decomposition of formic acid. ${ }^{[23]}$

We report herein that indeed, the use of an extracting phase with the bimetallic Ru@Pt NPs in 1-n-butyl-3-methylimidazolium hexafluorophosphate $\left(\mathrm{BMI}^{\mathrm{P}} \mathrm{PF}_{6}\right)$ allows not only the formation of 
CHE but also 1,3-CHD with unprecedented selectivity for the partial hydrogenation of benzene.

\section{Results and Discussion}

The most commonly used synthetic method for the generation of bimetallic core@shell MNPs is the reduction of a second metal onto pre-formed cores, but this generally leads to larger NPs $(>10 \mathrm{~nm}) .{ }^{[24]}$ Using the "template" method, small Ru@Pt NPs have been easily prepared in $\mathrm{BMI}_{\mathrm{PF}} \mathrm{F}_{6}$. The $\mathrm{Pt}(0)$ precursor was decomposed over a previously synthesised ruthenium core, while self-nucleation of $\mathrm{Pt}$ was inhibited by keeping the temperature above the nucleation temperature of $\mathrm{Pt}^{[18]}$ Thus, the reduction of $\left[\mathrm{Ru}(\mathrm{COD})(2-\text {-methylallyl })_{2}\right] \quad(\mathrm{COD}=1,3-$ cyclooctadiene) in $\mathrm{BMI}^{\mathrm{P}} \mathrm{F}_{6}$ at $75{ }^{\circ} \mathrm{C}$ for $18 \mathrm{~h}$ under 5 bar of hydrogen affords $\mathrm{Ru}(0)$ nanoparticles. ${ }^{[25]}$ The addition of $\left[\mathrm{Pt}_{2}(\mathrm{dba})_{3}\right](\mathrm{dba}=$ dibenzylideneacetone $)$ to the thus prepared $\mathrm{Ru}(0)$ nanoparticles in IL followed by treatment with molecular hydrogen (4 bar) at $75{ }^{\circ} \mathrm{C}$ for $24 \mathrm{~h}$ affords a black solution containing Ru@Pt nanoparticles of $2.9 \pm 0.1$ nm (Figure 1). These nanoparticles were characterised by Rutherford backscattering (RBS), transmission electron microscopy (TEM), scanning transmission electron microscopy (STEM), energydispersive X-ray spectroscopy (EDS), X-ray diffraction (XRD) and X-ray photoelectron spectroscopy (XPS). The RBS analysis shows a 2:1 Pt:Ru composition (Figure S1) indicating that half of the initial Ru was not incorporated in the bimetallic structure. Indeed, the Ru species not incorporated have been extracted during purification step (extraction with ethanol, benzene and pentane) as determined by ICP-OES analysis of the organic phase (Table S1).

The mean size diameter of Ru@Pt NPs determined from TEM $(120 \mathrm{kV})$ and HAADF-STEM $(300 \mathrm{kV})$ micrographs (Figure 1) are $2.8 \pm 0.1$ and $2.9 \pm 0.1 \mathrm{~nm}$, respectively. The NPs are well distributed and stable in the IL, as seen in Figures $1 \mathrm{a}$ and $1 \mathrm{~b}$. High-resolution HAADF-STEM images of isolated particles are also shown (insets). High-Z contrast allied to FFT analyses may indicate an excess of Pt surrounding the Ru@Pt particles. The typical $f c c$ feature of the Pt arrangement sometimes prevails in the HAADF-STEM analyses. In some images, Pt species are also easily observed outside the particles. Single-particle driftcorrected EDS profile was also acquired, supporting the observation of a Pt-rich Ru@Pt surface (Figure 2). The mean particle size of the Ru@Pt NPs (2.8-2.9 nm) is larger than those of the monometallic $\mathrm{Ru}(0)$ and $\mathrm{Pt}(0)$ (both approximately $2.5 \mathrm{~nm}$ ) prepared in ILs. The Ru@Pt NPs in the IL are stable and do not show any sign of agglomeration/aggregation after one week (Figure S2). Note that density functional theory calculations have been already reported to characterize the interactions between $\mathrm{BMI}^{\mathrm{P} F_{6}}$ IL and Ru@Pt model nanoclusters. ${ }^{[26]}$
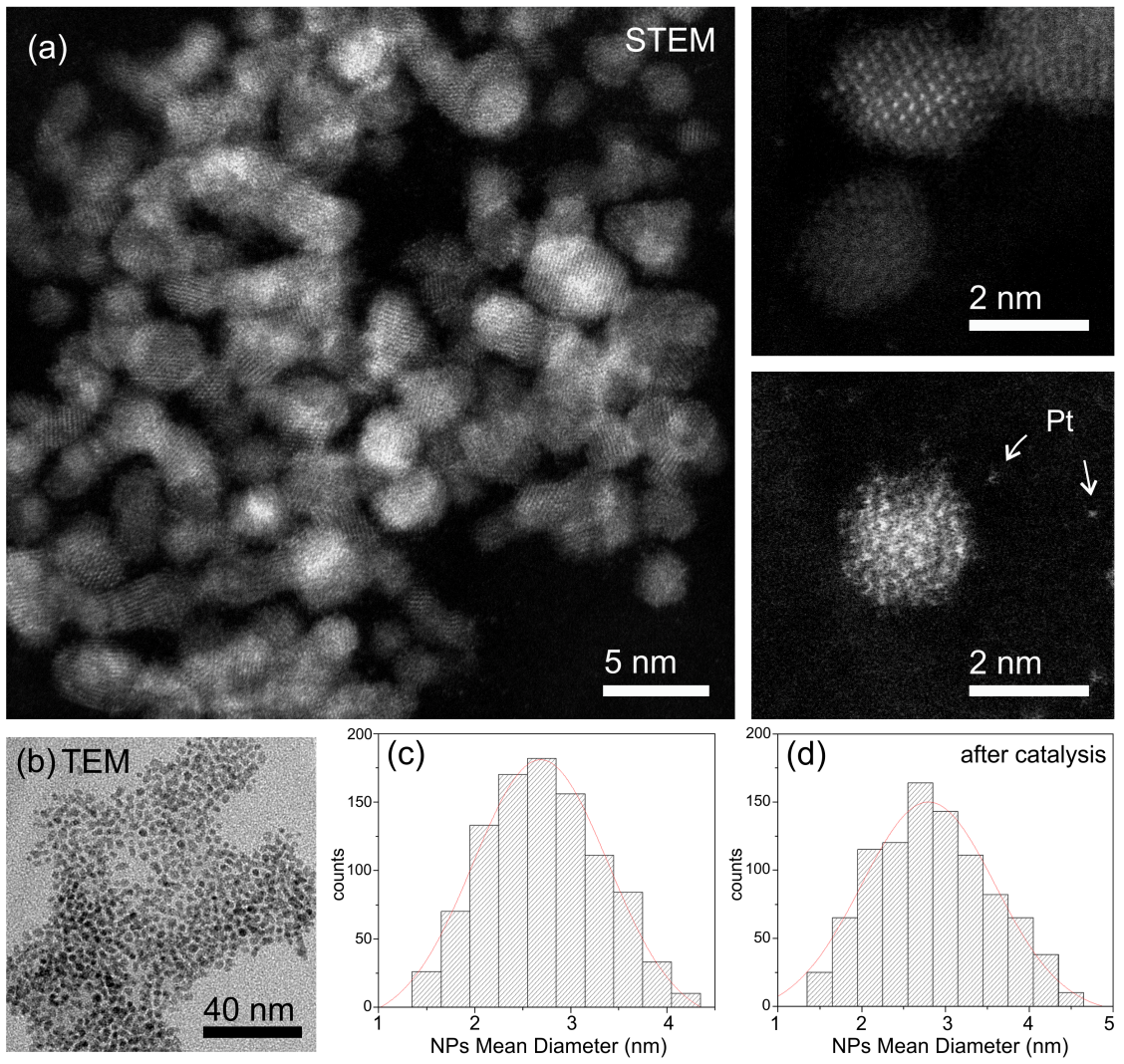

Figure 1. Micrographs of the Ru@Pt NPs in $\mathrm{BMI} . P F_{6}$; (a) HAADF-STEM (300 kV); (b) TEM (120 kV); size distribution histogram (c) before and (d) after catalysis. HAADF-STEM images of isolated Ru@Pt NPs are shown at insets. 
The metal-metal distances calculated from the XRD diffractogram of isolated Ru@Pt NPs are shifted, as compared to pure metals (Figure S3). The obtained diffractograms match with the one, which has been simulated for Ru@Pt (Figure S3) rather that with the one calculated for $\mathrm{Pt} / \mathrm{Ru}$ alloy and the monometallic $\mathrm{Pt}+\mathrm{Ru}$ aggregate mixture. ${ }^{[19,}$ 27] The highest convergence found with a Ru@Pt core-shell structure with a hexagonal closed packed ( $h c p)$ Ru-core and a face-centered cubic $(f c c)$ Pt-shell has an average size of $3.4 \mathrm{~nm}$, slightly larger than what was determined by TEM (Figure 1). However, the reflex for $\mathrm{Pt}(200)$ could not be detected. It is assumed that the intensity is lowered and shifted to lower degrees resulting in an overlapping with the $\mathrm{Ru}(101)$ reflex akin to what was observed earlier. ${ }^{[19]}$ Also, the $\mathrm{Pt}(220)$ is shifted to lower degrees, indicating a thicker platinum shell (Figure S3). The determined lattice parameters for ruthenium are in good accordance with theoretical values, while the refined lattice parameter for the platinum shell gives a cell parameter of $4.028 \AA$, which is slightly stretched compared with pure Pt $(3.9231 \AA),{ }^{[28]}$ indicating interactions between the Ru-core and Pt-shell. This is probably due to the poor crystalline Ru-core and/or to the partial entrance of Ru into the Pt-shell. ${ }^{[19]}$

Furthermore, the surface composition of the Ru@Pt NPs was investigated by XPS with two incident photon energies (1840 eV and $3000 \mathrm{eV})$. The wide-scan XPS spectrum indicates the presence of $\mathrm{Pt}, \mathrm{Ru}, \mathrm{O}, \mathrm{C}, \mathrm{N}, \mathrm{F}$ and $\mathrm{P}$ atoms (Figure S4). The oxygen atom is probably due to the oxidation of the metal surface during experimental manipulation and the fluorine, nitrogen, and phosphorus atoms are from the IL (no metal fluoride was observed).
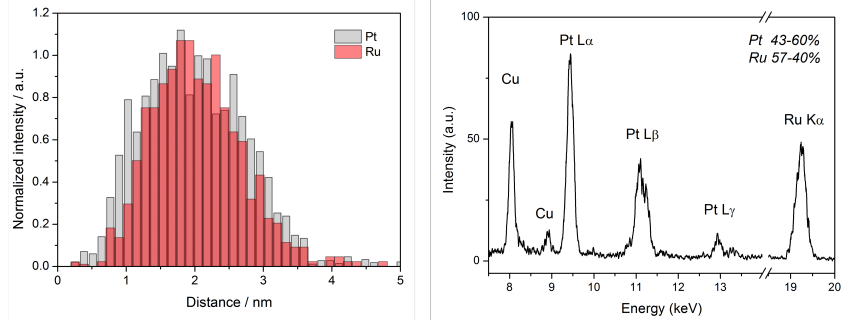

Figure 2. STEM-EDS profiles of the Ru@Pt before catalysis.

Figure 3 shows the XPS spectra in the Pt $4 f$ and $C 1 s+R u 3 d$ regions measured with incident photon energies $E_{p h}$ of 1840 and $3000 \mathrm{eV}$ before the catalytic reaction. The $\mathrm{Pt} 4 \mathrm{f}$ region (Figure 3a) reveals the presence of three different chemical states: $\operatorname{Pt}(0)$ at $70.9 \mathrm{eV}, \mathrm{Pt}(\mathrm{II})$ at $72.1 \mathrm{eV}$ and $\mathrm{Pt}(\mathrm{IV})$ at $74.9 \mathrm{eV} .^{[27,29]}$ The Ru $3 \mathrm{~d}$ region (Figure $3 \mathrm{~b}$ ) is close in energy to the $C 1 \mathrm{~s}$ region where it is possible to observe an overlapping between both regions. Since the carbon signal comes from different sources, it is hard to analyse the $\mathrm{Ru} 3 \mathrm{~d}$ region in this case. It is possible to observe that the $\mathrm{Ru} 3 \mathrm{~d}$ signal is composed of $11 \% \mathrm{Ru}(0)$ in the asprepared sample with the remaining signal coming from $\mathrm{Ru}$ in higher oxidation states. ${ }^{[16]}$ The change in the incident photon energy allows us to determine the atomic distribution inside the nanoparticles. ${ }^{[18]}$ In order to perform this study, the ratio was measured between the intensities of the Pt $4 f$ to $R u 3 p_{3 / 2}$ XPS regions normalised by the corresponding differential cross section and incident flux. ${ }^{[30]}$ The inelastic mean free path of photoelectrons ejected due to an incident photon energy of 1840 $\mathrm{eV}$ is around $18 \AA$ ( $\mathrm{Pt} 4 \mathrm{f}$ and $\mathrm{Ru} 3 \mathrm{p}_{3 / 2}$ regions), and for incident photon energy of $3000 \mathrm{eV}$, it is around $27 \AA$ ( $\mathrm{Pt} 4 \mathrm{f}$ region) and $29 \AA$ (Ru $3 p_{3 / 2}$ region). ${ }^{[31]}$ In this way, by comparing the XPS intensities from these two regions, it is possible to probe the $\mathrm{Ru}$ and $\mathrm{Pt}$ atoms at essentially the same depth of the sample. The ratio of intensities $\mathrm{Pt} 4 \mathrm{f} / \mathrm{Ru} 3 \mathrm{p}_{3 / 2}$ changes from $2.2\left(\mathrm{E}_{\mathrm{ph}}=1840\right.$ $\mathrm{eV})$ to $0.8\left(\mathrm{E}_{\mathrm{ph}}=3000 \mathrm{eV}\right)$. Since this ratio decreases when increasing the probed depth, it is consistent with an increase in the intensity of the $R u 3 p_{3 / 2}$ region compared to the intensity of the $\mathrm{Pt} 4 \mathrm{f}$ region at $E_{p h}=3000 \mathrm{eV}$. This result is evidence for the existence of a Ru-rich core and a Pt-rich shell region.
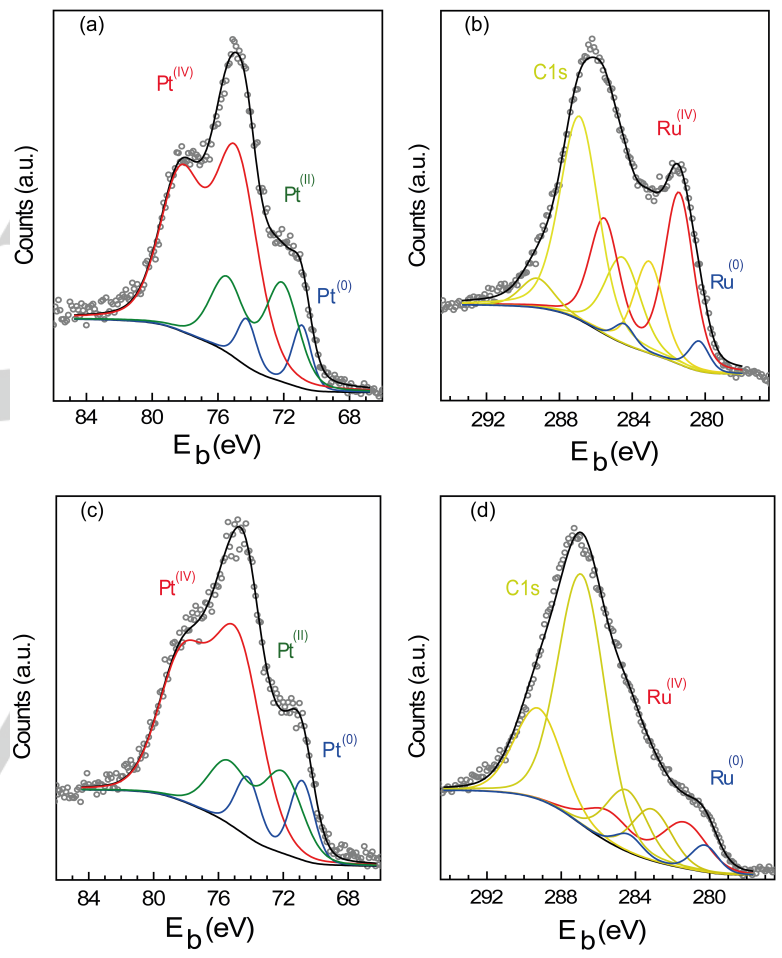

Figure 3. XPS measurements of Ru@Pt nanoparticles at Pt $4 \mathrm{f}((\mathrm{a})$ and (c)) and C 1s + Ru 3d ((b) and (d)) regions at $1840 \mathrm{eV}((\mathrm{a})$ and $(\mathrm{b}))$ and $3000 \mathrm{eV}$ $((c)$ and $(d))$.

For comparison purposes, $\mathrm{Pt}(0) \mathrm{NPs}(\sim 2.5 \mathrm{~nm}$ in mean diameter $)^{[32]}$ and $\operatorname{Ru}(0)(\sim 2.6 \mathrm{~nm} \text { in mean diameter })^{[17]}$ were prepared in $\mathrm{BMI}^{\mathrm{P} \mathrm{F}_{6}}$ using known procedures. It is known that the hydrogenation of benzene at $75^{\circ} \mathrm{C}$, under 4 bar of hydrogen by $\mathrm{Pt}(0)$ in $\mathrm{BMI}^{\mathrm{P} F_{6}}$ affords only $\mathrm{CHA}^{[18]}$ whereas $\mathrm{CHE}$ was detected at very low benzene conversion in the reaction performed with $\mathrm{Ru}(0) \mathrm{NPs}$ in $\mathrm{BMI}^{\mathrm{P} F_{6} .}{ }^{[17]}$ However, we found that by increasing the $\mathrm{H}_{2}$ pressure to 6 bar and reducing the temperature down to $60^{\circ} \mathrm{C}$, partial hydrogenated products (CHE and 1,3-CHD, Scheme 1) could be detected (Table S2). 


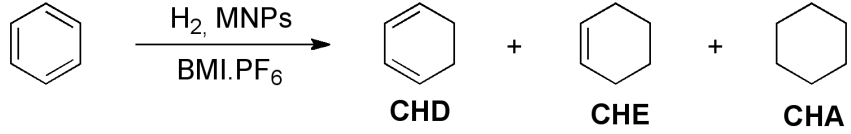

Scheme 1. Hydrogenation of benzene showing the possible products.

Only $\mathrm{CHA}$ was detected in the reaction performed with $\mathrm{Pt}(0)$ $\mathrm{NPs}$, whereas those performed with the Ru(0) NPs, CHE was observed in $12 \%$ selectivity and, to our delight, $1,3-\mathrm{CHD}$ in $23 \%$ selectivity at $1 \%$ benzene conversion (Table S2). In the case of bimetallic Ru@Pt NPs, the selectivity was 34\% in CHE (at $1 \%$ benzene conversion) and no CHDs were detected. This is a clear indication that the $\mathrm{Ru}$ core changes $\mathrm{Pt}$ shell properties since the reaction using monometallic $\mathrm{Pt}$ nanoparticles has no selectivity for the partial hydrogenation products, whereas the $\mathrm{Ru}$ @Pt shows relatively high selectivity for CHE (compare entries 1 and 3, Table S2).

When the hydrogenation reaction was performed in the presence of $2 \mathrm{~mL}$ of $n$-heptane using the same reactions conditions, 1,3-CHD was formed (see entries 4-6, Table S2) even in the case of $\mathrm{Pt}(0)$. However, 1,3-CHD was obtained in $27-33 \%$ selectivity when $\mathrm{Ru}(0)$ or Ru@Pt was used (entries 5 and 6, Table S2), although at very low benzene conversion (1\%) Most impressive, high selectivities (up to $21 \%$ ) for 1,3-CHD were achieved in the case of Ru@Pt NPs even at $5 \%$ benzene conversions (Figure 4).
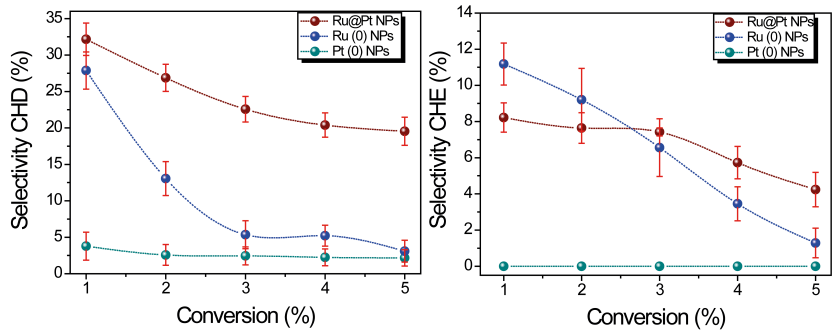

Figure 4. Selectivity of the partial hydrogenation products ((a) 1,3-CHD and (b) $\mathrm{CHE}$ ) vs. benzene conversion. Reaction conditions: $67 \mu \mathrm{mol}$ metal NPs, benzene/metal $($ mol ratio $)=670,1 \mathrm{~mL} \mathrm{BMI.PF}{ }_{6}, 60^{\circ} \mathrm{C}$ and 6 bar of $\mathrm{H}_{2}$. Cosolvent: $2 \mathrm{~mL} n$-heptane. Conversion and selectivity determined by GC.

It is worth noting that no significant changes on the mean diameter and size distribution of the NPs were observed by TEM and STEM after catalysis (Figures $1 \mathrm{c}$ and 1d, and see Figure S5). Moreover, the recovered catalytic IL dispersion could be reused at least three times with a small drop in the 1,3-CHD selectivity, from $21 \%$ to $17 \%$ after the third cycle (Figure S6). XPS analysis of the Ru@Pt NPs after catalysis revealed that the intensity of the components at the $\mathrm{Pt} 4 \mathrm{f}$ region $\left(\mathrm{E}_{\mathrm{ph}}=1840 \mathrm{eV}\right)$ changes from $9 \%(\mathrm{Pt}(0)), 25 \%(\mathrm{Pt}(\mathrm{II}))$ and $66 \%(\mathrm{Pt}(\mathrm{IV}))$ in the as-prepared sample to $43 \%(\operatorname{Pt}(0)), 46 \%(\operatorname{Pt}(\mathrm{II}))$ and $11 \%$ $(\mathrm{Pt}(\mathrm{IV}))$ after the catalytic reaction (Figure 5 and Figure S7).

The $\mathrm{Ru}(0)$ fraction also changes from $11 \%$ before to $31 \%$ after the reaction. It is clear from the XPS measurements that there is an enrichment of the skin layers of the nanoparticles with $\mathrm{Pt}$ atoms after catalysis (Figure 5). For a fixed photon incident energy of $1840 \mathrm{eV}$, the $\mathrm{Pt} 4 \mathrm{f} / \mathrm{Ru} 3 \mathrm{p}_{3 / 2}$ ratio increases from 2.2 (before) to 5.5 (after the catalytic reaction). These results provide evidence that the surface composition changes through surface segregation as nanoparticles are exposed to hydrogenation conditions, as usually observed in bimetallic NPs. ${ }^{[22,33-34]}$ Therefore, the drop on 1,3-CHD may be related to the structural changes on the metal surface.

At this stage of our investigations there are at least two possible explanations concerning the "apparent" fail on the standard principle of traditional catalysis in which a catalyst does not alter the final thermodynamic equilibrium of a reaction. First, the reaction is not catalytic, i.e, the benzene hydrogenation is stoichiometric vis-à-vis of the MNPs at such lower benzene conversions. However, this hypothesis can de discarded since TON $>30$ were obtained. Note that the catalytic reactions have been repeated several times by 3 different chemists in two different Laboratories (Brazil and UK) using distinct experimental setups.
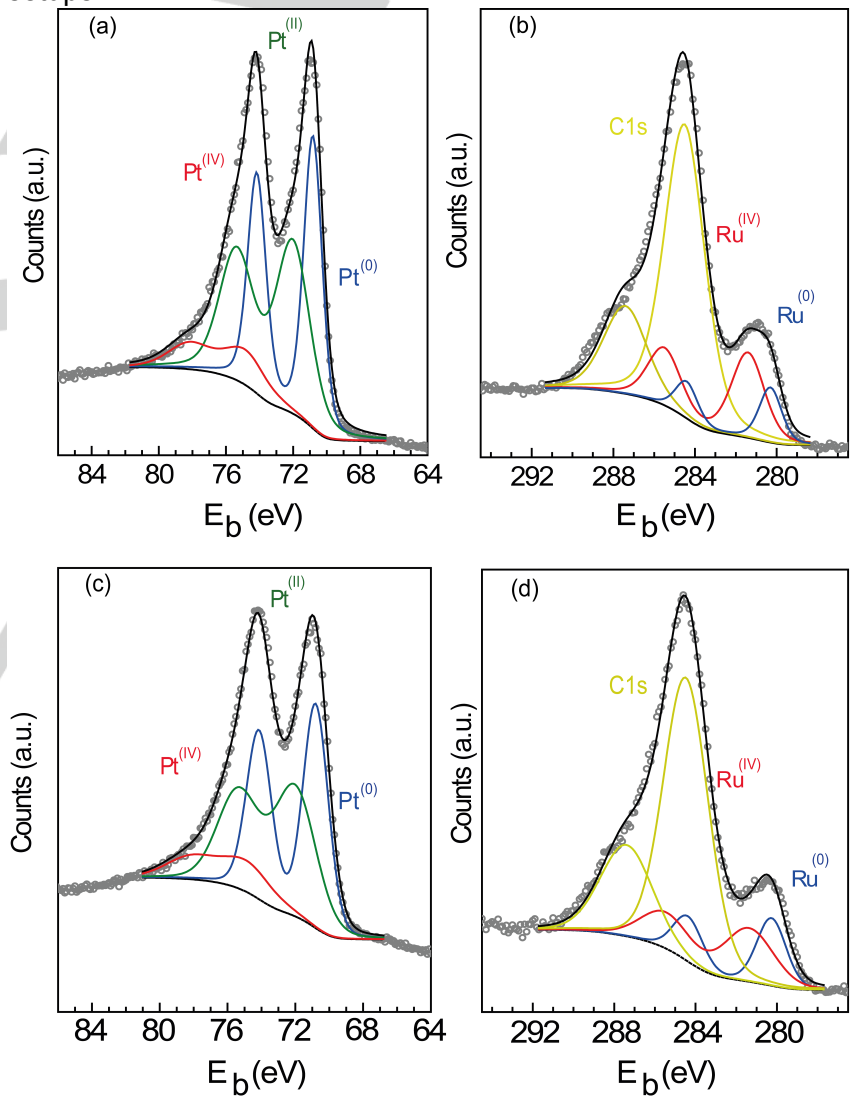

Figure 5. XPS measurements of Ru@Pt nanoparticles at Pt 4f ((a) and (c)) and C 1s + Ru 3d ((b) and (d)) regions at $1840 \mathrm{eV}((\mathrm{a})$ and $(\mathrm{b}))$ and $3000 \mathrm{eV}$ ((c) and (d)) after catalysis.

The second and most probably explanation is that under these asymmetric dynamic conditions (MNPs/ILs/organics/ $\mathrm{H}_{2}$ ) the reaction proceeds far from equilibrium ${ }^{[35]}$ and the reaction surface is better considered as a separate thermodynamic system $^{[36-39]}$ ("2-D reaction surface"). ${ }^{[36]}$ Indeed, chemical 
reactions far from equilibrium may exhibit various phenomena of temporal and spatial self-organization ${ }^{[40]}$ and complex transitory structures, ${ }^{[41]}$ as for example in $\mathrm{Pt}$ surface. ${ }^{[40]}$ Moreover, the viscoelastic model is probably the most adequate to describe the dynamic asymmetric mixture (MNPs/IL/organic substrates and products) since it is composed of fast and slow components, as in colloidal suspensions. ${ }^{[42]}$ Therefore, the IL/NPs catalytic system can be regarded as a chemically active membrane ${ }^{[43]}$

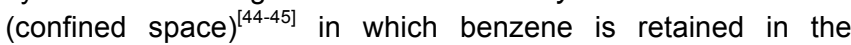
catalytic phase and the hydrogenated products (CHD, CHE and $\mathrm{CHA}$ ) are expelled akin to that observed in the partial hydrogenation of dienes by Pd based catalysts in neat ILs ${ }^{[46-48]}$ or supported in hybrid/IL materials. ${ }^{[49]}$

Hence, the catalytic system MNPs/IL/nheptane provides the conditions in which the 1,3-CHD formed is removed from the catalytic site probably by benzene/ $n$-heptane mixture. Indeed, in the reaction performed with the isolated Ru@Pt, i.e. without BMI.PF 6 , the 1,3-cyclohexadiene selectivity drops from $21 \%$ in IL to $5 \%$ without IL at $5 \%$ benzene conversion (Figure 6 ). Moreover, the reaction performed employing co-solvents such as dichloromethane, which is miscible with the IL, gave very low selectivity for the partial benzene hydrogenation products.
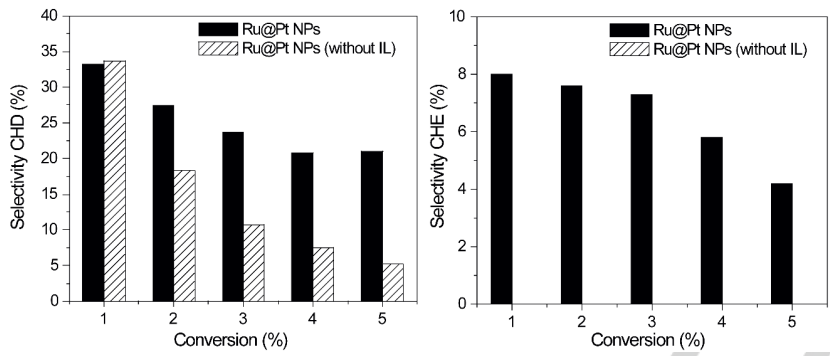

Figure 6. Selectivity of the products in the benzene hydrogenation catalysed by Ru@Pt NPs in the presence and absence of the IL BMI.PF 6 ( $1 \mathrm{~mL})$. Reaction conditions: $67 \mu \mathrm{mol}$ metal NPs, benzene/metal $(\mathrm{mol}$ ratio $)=670$, $60{ }^{\circ} \mathrm{C}$ and 6 bar of $\mathrm{H}_{2} ; 2 \mathrm{~mL}$ of $n$-heptane.

Moreover, benzene is at least 20 times more soluble in IL than the alkenes ${ }^{[17]}$ and thus can displace the relatively stable $\mathrm{CHD}$ from the metal surface. As expected, the selectivity in partial benzene hydrogenation products (1,3-CHD and CHE) decreases significantly with increasing benzene conversion, from $40 \%$ at $1 \%$ conversion to $26 \%$ at $5 \%$ conversion (Figure 4 ). No $1,4-\mathrm{CHD}$ was observed in any experiment using $\mathrm{Pt}(0), \mathrm{Ru}(0)$ or $\mathrm{Ru} @ \mathrm{Pt}$ nanoparticles indicating that the hydrogenation proceeds preferentially through 1,3-CHD intermediate.

The hydrogenation of benzene and 1,3-CHD is a structuresensitive reaction, ${ }^{[18]}$ whereas the hydrogenation of mono-alkene is not. The hydrogenation of benzene and 1,3-CHD should, in principle, occur only at specific sites on the metal surface, whereas the hydrogenation of CHE occurs on almost all of the surface metal active sites. Therefore, the Ru@Pt NPs in $\mathrm{BMI}_{\mathrm{PF}} / \mathrm{n}$-heptane provides the right environment to achieve higher selectivities for the mono-hydrogenation of benzene, i.e. reducing the contact of $\mathrm{CHD}$ with specific catalytic sites, mainly the surface atoms at which it was formed. This activation is very likely a result of the modification of the geometric/electronic structure of the $\mathrm{Pt}$ surface induced by the presence of subsurface $\mathrm{Ru}$ atoms. This modification accelerates the benzene partial reduction through a substantial stabilisation of the reactive intermediate $(1,3-\mathrm{CHD})$ that is expelled by benzene and removed from the IL catalytic phase by the hydrocarbon phase before it is hydrogenated to CHE. The origin of the Ru subsurface effect is very likely related to the distorted and more compressed $f c c$ Pt shells of the Ru@Pt NPs as compared to bulk $f c c$ Pt, as already observed for sub 5.0 nm Ru@Pt NPs. ${ }^{[18]}$ Note that the larger size of the Ru@Pt $(2.9 \mathrm{~nm})$ NPs compared to those of monometallic $\mathrm{Pt}(0) \mathrm{NPs}(2.5 \mathrm{~nm})$ implies only a small reduction of face to corner and edge surface atoms (from $55 \%$ to $48 \%$, assuming $f c c \mathrm{Pt}$ in both cases). ${ }^{[50]}$ Moreover, the $\mathrm{Pt}$ surface is more electrophilic in the Ru@Pt NPs than in Pt(0) NPs as observed by XPS (only $9 \%$ of $P t(0)$ in Ru@NPs against $37 \%$ in $\left.\mathrm{Pt}(0) \mathrm{NPs}^{[51]}\right)$. It is known that the affinity of benzene for its active site increases with decreasing the electron density of the surface metals. ${ }^{[1]}$ In turn, the electron-deficient NPs surface increases the stabilisation of the 1,3-CHD intermediate, and then allows its desorption.

\section{Conclusions}

We have demonstrated that small $(\sim 2.9 \mathrm{~nm})$, stable and well distributed BMI.PF 6 soluble Ru@Pt NPs can be easily prepared by a tandem reduction of $\mathrm{Ru}(\mathrm{II})$ followed by decomposition of $\mathrm{Pt}(0)$ organometallic precursors under hydrogen. The $\mathrm{Pt}(0)$ surface of these core-shell like Ru@Pt NPs display unprecedented catalytic properties towards the hydrogenation of benzene to $1,3-\mathrm{CHD}(21 \%$ at $5 \%$ benzene conversion) that is completely different from monometallic $\mathrm{Pt}(0)$ or $\mathrm{Ru}(0)$, which show "very low selectivities" for partial hydrogenated products under the same reaction conditions. The $\mathrm{Pt}$ electronic modification is very likely due to its higher electron deficiency provoked by the subsurface $\mathrm{Ru}$ atoms in which the "encapsulated" substrate/intermediate molecule can only adapt specific conformations as it has to adjust to the geometric and electronic features of the IL/NPs container. The fine-tuning of the reaction conditions, in particular the use of $n$-heptane, in the hydrogenation of benzene allows the formation of the partial hydrogenation product $1,3-\mathrm{CHD}$ in relatively high selectivity $(21 \%)$, although at low substrate conversion (5\%) using Ru@Pt NPs in BMI.PF 6 . These results indicate that metal NPs in highly organized ILs can operate far from the equilibrium (similar to a chemically active membrane) and thus open a new window of opportunities for the development of more selective "soluble" heterogeneous catalysts.

\section{Experimental Section}

General Information. All manipulations involving the metal complexes were carried out under an argon atmosphere using Schlenk or glovebox techniques. [Ru(COD)(2-methylallyl $)_{2}$ ] was obtained from Sigma-Aldrich and used without further purification. The BMI.PF $6{ }_{6}{ }^{[52]}\left[\mathrm{Pt}_{2}(\mathrm{dba})_{3}\right]^{[53]}$ and the $\operatorname{Ru}(0)^{[25]}$ and $\mathrm{Pt}(0)^{[32]} \mathrm{NPs}$ were prepared according to reported 
procedures. Benzene was degassed and stored under argon prior to use. All of the other chemicals were purchased from commercial sources and used without further purification. NMR spectra were recorded on a Varian VNMR spectrometer $(300 \mathrm{MHz})$

GC and GC-MS. GC analyses were run with an Agilent Technologies GC System 6820 with a FID detector and a DB-17 column ( $T$ injector = $250{ }^{\circ} \mathrm{C} ; \mathrm{P}=103 \mathrm{kPa}$; $\mathrm{T}$ program $=10 \mathrm{~min}$ at $40{ }^{\circ} \mathrm{C}, 10{ }^{\circ} \mathrm{C} / \mathrm{min}$ until $250{ }^{\circ} \mathrm{C}$, then $10 \mathrm{~min}$ at $250^{\circ} \mathrm{C}$ ). GC-MS analyses were run with a Shimadzu QP50 with a Rtx-5MS column; $\mathrm{T}$ injector $=250{ }^{\circ} \mathrm{C} ; \mathrm{P}=103$ $\mathrm{kPa}$; T program $=10 \mathrm{~min}$ at $40{ }^{\circ} \mathrm{C}, 10{ }^{\circ} \mathrm{C} / \mathrm{min}$ until $250{ }^{\circ} \mathrm{C}$, then $10 \mathrm{~min}$ at $250^{\circ} \mathrm{C} ; \mathrm{El}=70 \mathrm{eV}$ )

Preparation of Ru@Pt NPs. A standard reaction: a Fischer-Porter bottle was loaded in the dry-box with the precursor [Ru(COD)(2-methylallyl) $\left.{ }_{2}\right]$ $(64.5 \mathrm{mg}, 0.2 \mathrm{mmol})$ and $6 \mathrm{~mL}$ BMI.PF 6 . The system was stirred under vacuum for $20 \mathrm{~min}$ and heated until $75{ }^{\circ} \mathrm{C}$. Then, 5 bar hydrogen was added to the system and kept reacting for $18 \mathrm{~h}$ at $75^{\circ} \mathrm{C}$. The obtained black suspension was evacuated to remove the volatiles. Then, to the formed Ru nanoparticles, a solution of $\left[\mathrm{Pt}_{2}(\mathrm{dba})_{3}\right](110 \mathrm{mg}, 0.1 \mathrm{mmol})$ in $10 \mathrm{~mL}$ acetonitrile was added. All volatile compounds were removed under reduced pressure at $75{ }^{\circ} \mathrm{C}$ and 4 bar of hydrogen were added. After $24 \mathrm{~h}$ the black solution was washed with benzene $(3 \times 20 \mathrm{~mL})$, ethanol $(3 \times 10 \mathrm{~mL})$ and pentane $(3 \times 30 \mathrm{~mL})$. Again, the system was evacuated to remove all volatile compounds. The formed nanoparticles were stored under argon at $-20{ }^{\circ} \mathrm{C}$. The nanoparticles were analysed by transmission electron microscopy (TEM), scanning transmission electron microscopy (STEM), energy-dispersive X-ray spectroscopy (EDS), X-ray photoelectron spectroscopy (XPS) and electron and X-ray diffraction (XRD). For XRD analysis the NPs were isolated by centrifugation with the addition of THF $(10 \mathrm{~mL})$ and washed with $\mathrm{DCM}(10 \times 10 \mathrm{~mL})$, ethanol $(10$ $\times 10 \mathrm{~mL})$ and pentane $(3 \times 10 \mathrm{~mL})$ and dried under reduced pressure.

Hydrogenation of Benzene. As a general procedure, a solution of benzene $(4 \mathrm{~mL}$, benzene/catalyst $=670)$ with a co-solvent $n$-heptane $(2$ $\mathrm{mL}$ ) was added to a Fischer-Porter reactor that contained the appropriate amount of catalyst $(67 \mu \mathrm{mol}$ of metal NPs) dissolved in BMI.PF $_{6}(1 \mathrm{~mL})$. The reactor was pressurised with 6 bar of $\mathrm{H}_{2}$ at $60{ }^{\circ} \mathrm{C}$. Sample was taken from the reaction mixture every $10 \mathrm{~min}$. After the desired reaction time, the reactor was cooled to room temperature and depressurised. GC and GC-MS analysis (Figures S8-S10) of the samples were used to determine conversions and selectivities.

RBS measurements were carried out in a $3 \mathrm{MV}$ Tandetron accelerator using a $\mathrm{He}^{+}$ion beam of $1.5 \mathrm{MeV}$ at IF/UFRGS. The Si surface-barrier detector was positioned at a scattering angle of $165^{\circ}$

TEM and STEM. TEM analysis was performed using a JEOL JEM 1200 Exll operating at $80 \mathrm{kV}$. TEM samples were prepared by dropping the acetone-diluted solution of the isolated Ru@Pt nanoparticles onto a copper TEM grid. Ruthenium and Platinum content were determined by EDS using a NORAM Pioneer spectrometer with a beam energy of 200 kV. STEM and high-resolution TEM (HRTEM) were performed using a XFEG Cs-corrected FEI Titan 80/300 microscope at INMETRO operated at 80 and $300 \mathrm{kV}$. High Z-contrast images were acquired through STEM using a high angle annular dark field detector (HAADF) and a semiconvergence angle of $27.4 \mathrm{mrad}$. Spatial-correlated EDS profile experiments were carried out using $\mathrm{K}$ and $\mathrm{L}$ lines from $\mathrm{Ru}$ and $\mathrm{Pt}$. The typical lateral resolution was greater than $0.1 \mathrm{~nm}$.

XPS. For the XPS measurements, the powder of the Ru@Pt nanoparticles was spread out over the carbon tape and introduced into the analysis chamber at the D04A-SXS beam-line endstation ${ }^{[6]}$ at LNLS.
The sample was investigated using the long scan, $R u 3 d, R u 3 p_{3 / 2}$, Pt $4 f$, $\mathrm{O} 1 \mathrm{~s}$ and $\mathrm{C}$ 1s scan regions. The spectra were collected using an InSb (111) double crystal monochromator at fixed photon energies of 1840 and $3000 \mathrm{eV}$. The hemispherical electron analyser (PHOIBOS HSA3500 $150 \mathrm{R} 6$ ) was set at a pass energy of $30 \mathrm{eV}$, and the energy step was 0.1 $\mathrm{eV}$, with an acquisition time of $100 \mathrm{~ms} /$ point. The overall resolution was around $0.3 \mathrm{eV}$. The base pressure used inside the chamber was around $1.0 \times 10^{-9} \mathrm{mbar}$. The monochromator photon energy calibration was done at the Si K edge $(1839 \mathrm{eV})$. An additional calibration of the analyser's energy was performed using a standard $\mathrm{Au}$ foil $\left(\mathrm{Au} 4 \mathrm{f}_{7 / 2}\right.$ peak at $83.8 \mathrm{eV}$ ). We also considered the $\mathrm{C}$ 1s peak value of $284.5 \mathrm{eV}$ as reference to verify possible charging effects. The XPS measurements were obtained at a $45^{\circ}$ take off angle at room temperature.

XRD. The XRD patterns were recorded for a $2 \theta$ range of $20^{\circ}$ to $90^{\circ}$ with a $0.05^{\circ}$ step size and measurement time of $1 \mathrm{~s}$ per step with $\mathrm{Cu} \mathrm{Ka}$ radiation $(\lambda=1.54 \AA)$ and monochromator of graphite. Data processing was performed by the Rietveld method using FullProf software. The instrumental resolution function (IRF) of the diffractometer was obtained from the $\mathrm{LaB}_{6}$ standard.

\section{Acknowledgements}

The authors thank NULAM/DIMAT-INMETRO and LNLS for the use of the TEM microscopes and the beam-line, respectively. A. W. acknowledges the DAAD for a scholarship. M. H. G. P. is grateful for financial support by the DFG (Heisenberg-Program).

Keywords: nanoparticles $\bullet$ ionic liquids $\bullet$ hydrogenation $\bullet$ nonequilibrium • arenes

[1] L. Foppa, J. Dupont, Chem. Soc. Rev. 2015, 44, 1886-1897.

J. A. Don, J. J. F. Scholten, Faraday Discuss. 1981, 72, 145

M. Boudart, Adv. Catal. 1969, 20, 153-166.

G. A. Somorjai, J. Carrazza, Ind. Eng. Chem. Fund. 1986, 25, 63 69.

[5] K. M. Bratlie, H. Lee, K. Komvopoulos, P. Yang, G. A. Somorjai, Nano Lett. 2007, 7, 3097-3101.

[6] L. Zhu, Y. Jiang, J. Zheng, N. Zhang, C. Yu, Y. Li, C. W. Pao, J. L. Chen, C. Jin, J. F. Lee, C. J. Zhong, B. H. Chen, Small 2015, 11 4385-4393.

[7] M. M. Stalzer, C. P. Nicholas, A. Bhattacharyya, A. Motta, M Delferro, T. J. Marks, Angew. Chem. Int. Ed. 2016, 55, 5263-5267.

[8] P. J. Dyson, Dalton Trans. 2003, 2964-2974. 375-378.

[10] K. Yamashita, H. Obana, I. Katsuta, Vol. EP552809A1, Asahi

Kasei Kogyo K. K., 1993, p. 31 pp.

[11] C. Morin, D. Simon, P. Sautet, Surf. Sci. 2006, 600, 1339-1350.

[12] M. Saeys, M. F. Reyniers, M. Neurock, G. B. Marin, J Phys Chem B 2005, 109, 2064-2073.

[13] H. Imamura, K. Nishimura, K. Sumioki, M. Fujimoto, Y. Sakata, Chem. Lett. 2001, 450-451.

[14] X. Su, K. Kung, J. Lahtinen, R. Y. Shen, G. A. Somorjai, Catal. Lett 1998, 54, 9-15.

[15] B. E. Koel, D. A. Blank, E. A. Carter, J. Mol. Catal. A: Chem. 1998 131, 39-53.

[16] F. Schwab, M. Lucas, P. Claus, Angew. Chem. Int. Ed. 2011, 50, 10453-10456.

[17] E. T. Silveira, A. P. Umpierre, L. M. Rossi, G. Machado, J. Morais, G. V. Soares, I. L. R. Baumvol, S. R. Teixeira, P. F. P. Fichtner, J. Dupont, Chem. Eur. J. 2004, 10, 3734-3740.

S. Alayoglu, P. Zavalij, B. Eichhorn, Q. Wang, A. I. Frenkel, P. Chupas, ACS Nano 2009, 3, 3127-3137.

[19] S. Alayoglu, A. U. Nilekar, M. Mavrikakis, B. Eichhorn, Nature Mater. 2008, 7, 333-338. 
X. Yuan, G. Sun, H. Asakura, T. Tanaka, X. Chen, Y. Yuan, G. Laurenczy, Y. Kou, P. J. Dyson, N. Yan, Chem. Eur. J. 2013, 19 1227-1234.

[21] N. J. Brown, A. Garcia-Trenco, J. Weiner, E. R. White, M. Allinson, Y. Chen, P. P. Wells, E. K. Gibson, K. Hellgardt, M. S. P. Shaffer, C. K. Williams, ACS Catal. 2015, 5, 2895-2902. D. O. Silva, L. Luza, A Gual, D. L. Baptista, F. Bernardi, M. J. M. Zapata, J. Morais, J. Dupont, Nanoscale 2014, 6, 9085-9092.

[23] K. Tedsree, T. Li, S. Jones, C. W. A. Chan, K. M. K. Yu, P. A. J. Bagot, E. A. Marquis, G. D. W. Smith, S. C. E. Tsang, Nature Nanotechnol. 2011, 6, 302-307.

[24] C. J. Serpell, J. Cookson, D. Ozkaya, P. D. Beer, Nat. Chem. 2011 3, 478-483.

[25] M. Prechtl, M. Scariot, J. Scholten, G. Machado, S. Teixeira, J. Dupont, Inorg. Chem. 2008, 47, 8995-9001.

[26] P. Cheng, C. Liu, Y. Yang, S. Huang, Chem. Phys. 2015, 452, 1-8.

[27] C. W. Scheeren, G. Machado, S. R. Teixeira, J. Morais, J. B. Domingos, J. Dupont, J. Phys. Chem. B 2006, 110, 13011-13020. A. V. Chichagov, A. B. Belonozhko, A. L. Lopatin, T. N. Dokina, O. L. Samokhvalova, T. V. Ushakovskaya, Z. V. Shilova, Kristallografiya 1990, 35, 610-616.

[29] C. D. Wagner, W. M. Riggs, L. E. Davis, J. F. Moulder, G. E. Muilenberg, Handbook of X-Ray Photoelectron Spectroscopy, Perkin-Elmer Co., 1979.

[30] J. J. Yeh, I. Lindau, At. Data Nucl. Data Tables 1985, 32, 1-155.

[31] S. Tanuma, C. J. Powell, D. R. Penn, Surf. Interface Anal. 1991, 17, 911-926.

[32] C. W. Scheeren, G. Machado, J. Dupont, P. F. P. Fichtner, S. R. Texeira, Inorg. Chem. 2003, 42, 4738-4742.

[33] H. Liao, A. Fisher, Z. J. Xu, Small 2015, 11, 3221-3246.

[34] F. Bernardi, M. C. M. Alves, A. Traverse, D. O. Silva, C. W. Scheeren, J. Dupont, J. Morais, J. Phys. Chem. C 2009, 113, 3909-3916.

G. M. Whitesides, B. Grzybowski, Science 2002, 295, 2418-2421.

L. Zhu, G. Frens, J. Phys. Chem. B 2006, 110, 18307-18312.

D. P. Sheehan, Phys. Rev. E 2013, 88, 032125.

D. Bedeaux, S. Kjelstrup, L. Zhu, G. J. Koper, Phys. Chem. Chem. Phys. 2006, 8, 5421-5427.

[39] V. N. Parmon, Catal. Today 1999, 51, 435-456.

[40] S. Jakubith, H. H. Rotermund, W. Engel, A. von Oertzen, G. Ertl, Phys. Rev. Lett. 1990, 65, 3013-3016.

[41] E. Rabani, D. R. Reichman, P. L. Geissler, L. E. Brus, Nature 2003 426, 271-274.

[42] H. Tanaka, J. Phys.: Condens. Matter 2000, 12, R207-R264.

[43] J. Yi, L. L. Tavlarides, AlChE J. 1992, 38, 1957-1968.

[44] S. H. Leenders, R. Gramage-Doria, B. de Bruin, J. N. Reek, Chem. Soc. Rev. 2015, 44, 433-448.

[45] R. A. Schoonheydt, B. M. Weckhuysen, Phys. Chem. Chem. Phys. 2009, 11, 2794-2798.

[46] A. P. Umpierre, G. Machado, G. H. Fecher, J. Morais, J. Dupont, Adv. Synth. Catal. 2005, 347, 1404-1412.

[47] J. Dupont, P. Suarez, A. Umpierre, R. de Souza, J. Braz. Chem. Soc. 2000, 11, 293-297.

[48] C. Consorti, A. Umpierre, R. de Souza, J. Dupont, P. Suarez, J. Braz. Chem. Soc. 2003, 14, 401-405.

[49] L. Luza, C. P. Rambor, A. Gual, F. Bernardi, J. B. Domingos, T. Grehl, P. Brüner, J. Dupont, ACS Catal. 2016, 6, 6478-6486.

[50] A. P. Umpierre, E. de Jesus, J. Dupont, ChemCatChem 2011, 3, 1413-1418.

[51] C. Scheeren, G. Machado, S. Teixeira, J. Morais, J. Domingos, J. Dupont, J. Phys. Chem. B 2006, 110, 13011-13020.

[52] P. A. Z. Suarez, J. E. L. Dullius, S. Einloft, R. F. De Souza, J. Dupont, Polyhedron 1996, 15, 1217-1219.

[53] C. Pan, F. Dassenoy, M. J. Casanove, K. Philippot, C. Amiens, P. Lecante, A. Mosset, B. Chaudret, J. Phys. Chem. B 1999, 103, 10098. 


\section{Entry for the Table of Contents}

\section{FULL PAPER}

It is reported the first partial hydrogenation of benzene to 1,3cyclohexadiene in a catalytic biphasic system (a "chemically active membrane-like") composed of Ru@Pt nanoparticles in ionic liquid.

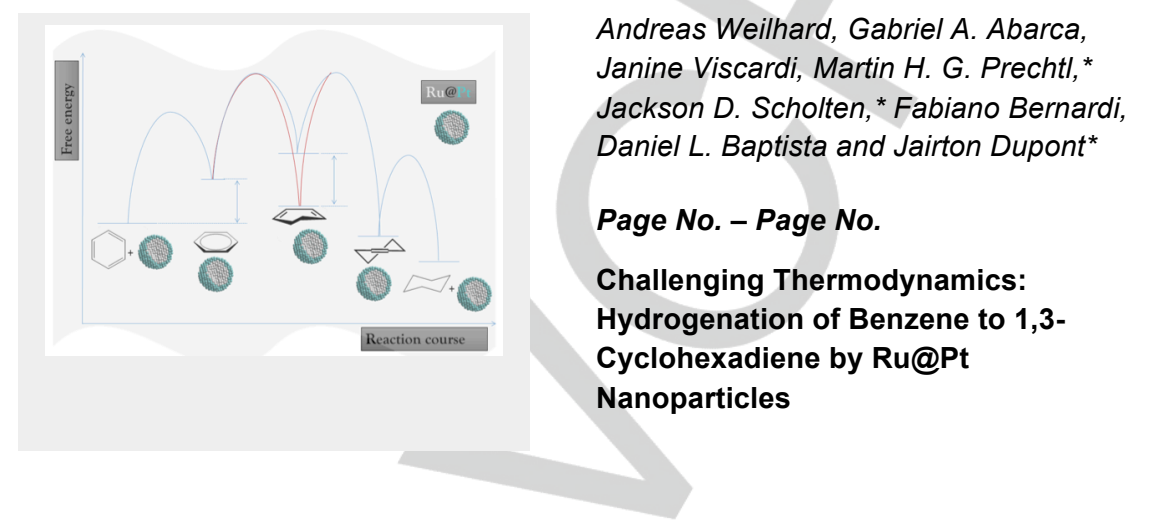

